\title{
Tactical Awareness in the Teaching of Football in Colleges and Universities
}

\author{
Min Li ${ }^{1}$, Ming Zhang ${ }^{2}$ \\ ${ }^{1}$ Institute of Technology, East China Jiaotong University, China \\ ${ }^{2}$ Jiangxi Vocation College of Ahead Software, China
}

Key words: Football in colleges and universities, Football teaching, Tactical awareness, teaching

\begin{abstract}
Influenced by the exam oriented education in China, the football knowledge for the college students is almost zero and the football level is worrying in China. So how to cultivate the football ability of the students in the university? Cultivating students' tactical awareness is a good recipe to improve the physical and technical level of the students, and can improve the students' football ability different from other colleges and universities. In this paper, the author analyzes the connotation and training methods of student's tactical awareness in football teaching from various aspects, hoping to improve students' ability of football strategy and mental accomplishment, and to improve their football ability.
\end{abstract}

Football is a very mobile sport, it requires the athletes to control the football effectively in the competition, with very strong tactical and tactical awareness, to control the overall situation and control the situation. In recent years, the development of new curriculum reform has made the football in colleges and universities developed rapidly. However, we also see that the level of students' skills and tactics has not been improved correspondingly. How to improve the students' technical and tactical level, to cultivate the tactical awareness, and then to improve the students' football ability? The author starts with the connotation and characteristics of tactical awareness, and then puts forward some feasible ways to cultivate students' tactical awareness.

\section{The connotation of tactical awareness}

The so-called tactical awareness refers to the reflection of the tactical changes in the two sides of the war on the regularity of the respective players' brains in a football match. That is to say, athletes should choose the instant decision-making ability of technology and tactics according to the change of environment, which is formed spontaneously in competition. Tactical awareness is the experience, ability and knowledge embodied in the movement of athletes, and is a high generalization of athletes' ability to judge, strain, and complete techniques and tactics in competitions. The author finds that in actual football matches, athletes or students have received tactical awareness control for every skill and tactic ability, so the cultivation of tactical awareness is very important. This is because the level of tactical awareness determines the understanding and grasp of the players' or students' understanding of the tactical requirements for a coach or a teacher. It is a good athlete or student's level to discover the objective rules in the competition, predict the situation on the spot accurately and timely, and use related skills and tactics spontaneously, this is the level that an excellent athlete or student should have.

\section{The characteristics of tactical awareness in college football teaching}

\subsection{Conscious purposiveness}

In the teaching of football in colleges and universities, the students' action ability should be in accordance with the tactical goals. That is to say, students should understand the relevant tactical intentions of the teacher, in order to achieve the purpose of effective attack or effective defense. This purpose and result will enable the students to "implant" the relevant tactical awareness into the 
student's mind before the relevant tactical activities are carried out. Therefore, the general teacher will make the relevant goals, methods and tactics in advance, and then arrange the students to carry out the tactics.

\subsection{Antagonism}

"Tactics" generally refers to the methods and means of action taken by the opposing sides to gain advantages. In the football game, whether the students are defensive or offensive, the tactical movements they used are reflected in the characteristics of antagonism. That is to say, in the process of tactical cooperation, students have been conducting restrictions and counter restrictions, which is the embodiment of the antagonistic characteristics for tactical awareness.

\subsection{Foreseeability}

In a football match, the change on the field is unforeseeable, so how to gain the advantage and even win the victory? In order to achieve the greatest advantage, students must take a look at the changes on the court, predict the offensive and defensive situations of the players and take effective measures to deal with them, which is the foresight feature in tactical awareness.

\subsection{Crypticity}

On the court, the parties in order to occupy the superiority and initiative, we must take effective measures to defense, require students to master a variety of technical movements, such as fake or covert action to interfere or confuse each other action, hide their tactical intent, to seize the initiative in the game. This is the concrete embodiment of the concealment for the students' football tactics consciousness.

\section{The training path of tactical awareness in the teaching of football in colleges and universities}

For football, it belongs to a cooperative team sport, so the training of fighting consciousness is essential. In the process of football training, not only can improve the cooperation consciousness between students, promote the development of the whole team, but also can help students to exercise their creative thinking, to combine the problems in actual combat with previous experience and theory, thereby enhance the combat capability.

\subsection{Pay attention to theoretical study}

Nowadays, scientific training has become the common understanding in the current college football teaching through the practice from scientific theory. The thinking characteristics of college students determine that they can not only study the theoretical knowledge, but also be able to innovate and apply them. In football field, teachers need to organize training according to their own conditions, and must not neglect training details and physical condition of every student to carry out the training, in this way, will not only cause the training effect is low, but also affect the body of students. But if the students can use the scientific knowledge, give full play to the subjective initiative and learn to use it, the football teaching will be twice the result of half the effort. Therefore, teachers should cultivate students' football awareness, guide them to use scientific theory and methods, and practice them.

\subsection{Strengthen psychological quality}

First of all, mental quality training is a long-term process, students need to do well in psychological quality training, they must stick to long-term and systematic principles and keep practicing repeatedly to form good psychological quality. Training psychology is like training technology, tactics and body, is a long process and must persist in doing systematic exercises, in this way, we can develop good mental accomplishment through repeated repetition. The psychological training should be done from the goal team of the college students, that is to say, football teachers should effectively train students' cognitive process, emotional process, will process and personality psychological characteristics during technical and tactical training and competition. 
Secondly, research shows that nowadays, there are five major psychological barriers in student carrier and learning, such as weak emotion control, weak willpower, distraction in competition, lack of self-confidence and personality characteristics, so teachers should grasp the key problems of students, which differs from different people, rapidly analyzes the shortcoming of students, targeted for training. Finally, the author finds that when we are carrying out football training, we should combine psychological, technical and physical training simultaneously, and integrate it into daily training, so that we can get the synchronous development of physical and mental quality, and we can solve the problem of sports disorder.

\subsection{Combine with the football lessons to train}

We should see that in the training of the students' tactical awareness, we can not lack the training of their basic skills. Because students only use good technology as the basis, and under the guidance of excellent tactical awareness, the best benefit can be obtained. Therefore, it is the general trend to cultivate the students' tactical awareness, and the mastery and application of related technology is closely related to the training of tactical awareness. To carry out technical training, we first need to let students clearly understand the purpose of learning technology, clarify the conditions and time of using this technology, standardize and correctly apply technology, and keep speed. Secondly, students should have a comprehensive grasp of relevant football skills, because it is not only the basis for completing tactics, but also the premise for flexible use of tactics, and the perfect sublimation of tactics. Only with excellent technology, we can make the action more reasonable and carry out the teacher's idea more effectively. Finally, students should keep the concept of field and the concept of their opponents at all times in training. That is to say, students should be always keeping the concept of goal and have a certain understanding of the technical actions of teammates, so that they can achieve the coordination cooperation.

\subsection{Cultivate sports intelligence}

For college students, sports intelligence is an essential part of training the consciousness of football tactics. In daily training and competition, the ability of perception is the beginning of the student's sports intelligence, and the ability of thinking and imagination are the key points. This ability can let students in football practice, to seize the warplanes in an unpredictable environment, quickly adjust the tactics. Sports intelligence is mainly composed of the ability of motion perception, sports memory, sports attention and sports thinking. To cultivate students' sports intelligence, we should strengthen the learning of students' football theory knowledge, expand the horizons of students. Teachers should cooperate with professionals who have exercise physiology and psychology in the development of the teaching for football tactics consciousness, to discover and solve problems together. Teachers should learn to apply the scientific method to evaluate the intelligence level of students, guide the students to a comprehensive, healthy and steady growth. Teachers should be added to the intelligence training into the daily training, to ensure that the objectives and plans to enhance the level of the players.

\subsection{Rehearsal in confrontation}

The tournament is also an important way to cultivate students' awareness of the fighting, the main purpose of competition training is to enable students to summarize the experience from practice, to analyze and excavate fighting methods, to let the students to train with theoretical knowledge, so as to achieve the combination of theory and practice, to train the ability of observation, reaction and strain. The ability of observation, reaction, analysis and strain requires the students to strengthen and accumulate in constant actual combat. Without confrontation training and actual combat, the students' tactical awareness can not be fully expressed and strengthened. In combat training and practice, students should enhance the observation and judgment ability, be able to take the initiative, seize the preemptive, be good at grasping the position and timing of attack and defense, to choose the time, strength, point, and direction when pass the football, to obtain the favorable opportunity, hide the spot intention, enhance the judgment and flexibility, the flexible use 
of tactics, in order to increase the control of the game, pay attention to the changes of false movement, eyesight and sport rhythm, to pass the football more, and dribble the football less.

\section{Conclusion}

The level of football tactical awareness is an important index to evaluate the level of the students' sports level. For students, the cultivation of football technology and tactical awareness for students, is to let the students do a perfect combination of physical and mental, and take the initiative in combat, the cultivation of football technical and tactical awareness for students, will be carried out simultaneously, in order to achieve good results, to promote students' long-term and all-round development.

\section{References}

[1] Hundeng Zheng. The cultivation of football awareness for students in colleges and universities [J]. Journal of North China Coal Medical University, 2010,12.

[2] Xiaoping Qi, Ciyu Yang, Xianqing Li. Research on the forced defense tactics for football [J]. Journal of Chengdu Sport University, 2006, 1.

[3] Hongyuan Guo. The cultivation of the tactical awareness for the football team in the national institutions [J]. Journal of Lanzhou college of Arts and Sciences (Natural science edition), 2015, 3.

[4] Xuelei Guan and so on. The cultivation of football awareness in the course of football options in colleges and universities [J]. Journal of Beijing Sport University, 2004,12.

[5] Yonggang Zhang. The cultivation of football consciousness for college students in general colleges and universities [J]. Scientific and technological information, 2007,12.

[6] Hongji Zhang. Analysis on the function of consciousness in football sports [J]. high education window, 2010,8. 